remedy, should circumstances render it practicable, is some sort of sound-proof enclosure, the design of which may need careful attention both as regards weight and discontinuity of structure. There is, of course, no such thing as a sound-proof material, and success in sound insulation is largely a matter of design.

Certain large-scale operations may require 'sound-proof' buildings to mask them, the doors and windows of which should be heavy and closefitting and preferably situated on the side remote from that where the noise is liable to be regarded as a nuisance. Doors and windows, particularly high windows and skylights, may require to be doubled and, in extreme cases, it may be necessary to employ double walls mounted on independent foundations. Buildings in which noisy operations are carried on should, if possible, be put under the lee of larger buildings, which may afford advantageous shielding to the locality. In the interior of noisy buildings, it is usually beneficial to the workers to divide groups of noisy machinery, so far as may be possible, into smaller units, each in its own enclosure. Appreciable benefit may also result from lining walls and ceilings with acoustical absorbent, so preventing the noise level from building up unduly.

In the case of structure-borne noises, the remedy is discontinuity somewhere in the structure either in the form of an air gap or as resilient material, for example, under the foundations of noisy or vibrating machinery.

Modern building design and materials do not provide protection from noises, whether from inside or outside, like the more solid houses of a generation ago. The noise problem is accentuated in the case of the large blocks of flats which are being erected in all quarters, and which apparently are mainly adapted for quiet tenants who are prepared to conform in this respect to a landlord's reasonable requirements. The situation lies largely with local authorities, who should lay down building by-laws, setting forth minimum standards of acoustic insulation. The architect and builder have of necessity been driven from traditional methods of construction to meet the economic requirements and closer scientific designing of to-day. Discontinuity of structure and the use of massive and poorly conducting materials formerly provided defence against sound, but instead we now have monolithic structures which are not only thinner and lighter than the old, but also are composed of good conducting materials. The steel-framed and ferro-concrete building, cement mortar, hard bricks and plaster, to say nothing of a general ramification of central-heating, running water and other piping, have replaced the softer brickwork, lime mortar and plaster, wooden beams, joists and studding, and the localized piping of the older houses. No one pretends, of course, that we can go back to the old methods, but if we are to mitigate the noise nuisance in modern buildings, we must adopt measures which are best incorporated during the designing stage.

There is, too, another aspect which should be clearly appreciated, and that is, if sound insulation in buildings is desired, it has to be paid for. The public, at present enticed with a plethora of laboursaving devices by landlords of flats, has yet to learn that reasonable acoustic privacy is obtainable provided it is prepared to face a small proportionate increase in the rent.

\title{
Structure of Protein
}

THERE can be few problems of predominantly 1 chemical interest which are being attacked by such a variety of methods of investigation as that of protein structure. This was well illustrated by the symposium on protein chemistry held on September 3 in Section B (Chemistry) of the British Association, in which the contributions ranged in subject from biochemistry to mathematics, each justifying its inclusion either by the addition of some significant fact to the total sum of knowledge or by the formulation of a stimulating hypothesis to account for facts which still await complete explanation.

The foundation of protein chemistry as we know it to-day has been laid by organic chemistry, which, chiefly in the hands of Emil Fischer and his pupils, has provided not only detailed information concerning the composition of proteins, but above all the unquestionable demonstration of the peptide linkage as the predominant feature of their intramolecular structure. Moreover, through the development of improvements in peptide synthesis, particularly the carbobenzoxy method, organic chemistry has provided a wealth of material which has illuminated the mode of action of proteolytic enzymes and which now promises to throw light on the physico-chemical behaviour of proteins and even perhaps on their immunological specificity. These points were brought out by Prof. C. R. Harington (London) in opening the symposium, but he was at the same time at pains to emphasize that the peptide theory in its simplest form is 
unable to account for all the properties of proteins, which can only be explained by the assumption of subsidiary linkages within the molecule.

The importance of the peptide linkage was further emphasized by Dr. K. Linderström-Lang (Copenhagen), who pointed out that this linkage is the only one known with certainty to be attacked by proteolytic enzymes. These enzymes, as is well known, may be roughly classified into the proteinases which attack complete protein molecules or their higher degradation products, and the various peptidases which attack peptides at points adjacent to free amino or carboxyl groups or both. Dr. Linderström-Lang directed attention to the interesting evidence which has recently accumulated that the true proteinases owe their peculiar specificity to the fact that they can only attack peptide linkages remote from free dissociating groups.

One of the greatest advances in the understanding of the physico-chemical behaviour of aminoacids and proteins is due to the zwitterion theory introduced by Bjerrum in 1923. The development of this theory and the evidence for its applicability to amino-acids was discussed by Dr. A. Neuberger (London), who laid particular emphasis on the good agreement to be observed between the experimentally determined dissociation constants of amino-acids and those calculated on the basis of the theory; evidence derived from dissociation constants of amino-acids other than $\alpha$-amino-acids shows that such molecules exist in solution in a relatively unbent condition with the charged groups far apart, thus accounting for the high electrical moment required by the zwitterion theory. Dr. Neuberger proceeded further to demonstrate the fact that it is now possible to interpret the electrometric titration curve of a protein with reasonable accuracy in terms of the polyvalent amino-acids which it contains, the additional dissociating groups of these amino-acids being the factors which determine the electrochemical behaviour of the protein molecule as a whole.

The determination of the very large molecular weights of proteins is a matter of considerable difficulty, and no method has afforded more valuable information on this point than the ultracentrifugal method evolved by Svedberg. This procedure was described by Mr. J. St. L. Philpot (Oxford), and was illustrated by a very beautiful application in which the molecular weight of the enzyme xanthine oxidase was observed by its rate of sedimentation from a solution containing the enzyme system, methylene blue and iodate; the solution, at first colourless throughout, becomes coloured from the top downwards in the ultracentrifuge owing to re-oxidation of the leucomethylene blue by the iodate as the enzyme is removed.
The remaining two contributions to the symposium were chiefly concerned with the nature of the subsidiary linkage in the protein molecule, which was referred to by the opener. The evidence to be derived from X-ray measurements was discussed by Dr. W. T. Astbury (Leeds), who recalled his well-known earlier work on the structure of the keratins, showing these proteins to be made up of bundles of peptide chains joined by subsidiary linkages which might be either the disulphide linkage of cystine or so-called hydrogen bonds or covalent linkages of unknown nature. It was pointed out by Dr. Astbury that X-ray measurements indicate a transition in structure from the stretched keratin or myosin molecule, through the partly folded molecule of unstretched keratin as it occurs in hair, to the completely folded molecule of the 'globular' proteins such as insulin. The evidence provided by X-ray measurements regarding the mechanism of denaturation of proteins was also discussed; it appears that this process certainly involves rearrangement and unfolding of peptide chains, but it seems to the present writer at least that the real nature of the phenomenon remains as obscure to physicists as it is to chemists.

Of the various theories of protein structure which have been proposed from time to time, few are of greater interest than the 'cyclol' hypothesis advanced on geometrical reasoning by Dr. D. M. Wrinch (Oxford). This theory, which has already been presented in a series of communications to NATURE, was briefly outlined by Dr. Wrinch, who claimed with justice that it is in fact a logical development of the peptide hypothesis built up within the framework of existing knowledge. The criticism of Dr. Linderström-Lang that the cyclol molecule contains linkages of a type not known to be attacked by enzymes was met by Dr. Wrinch with the admission of the possibility of spontaneous breakdown of the structure following initial enzymic rupture of the normal peptide linkages, which it does in fact contain.

The symposium was closed by two brief but interesting contributions, from Dr. Irving Langmuir on the possibilities offered by the study of protein films, and from Dr. D. Jordan Lloyd concerning the important physico-chemical work of Cohn and his collaborators at Harvard.

The general impression left by the symposium was that the problem of protein structure can only be solved by a combination of all applicable methods of attack. The listener was left in no doubt as to the magnitude of the problem, but nevertheless with the feeling that improvements and new developments of technique are now forthcoming at a rate which affords justifiable hope of its solution in the not very distant future. 